\title{
Socio-demographic and Health Aspects Associated with the Quality of Life in the Elderly of the Family Health Strategy. An Analytical Study
}

\begin{abstract}
Bruno Araújo da Silva Dantas ${ }^{1}$, Aline Maino Pergola-Marconato ${ }^{2}$, Jéssica Maria Arouca de Miranda ${ }^{3}$, Neidjany Patrícia Lima Torres ${ }^{4}$, Luana de Azevedo Souza ${ }^{5}$, Vanessa Ferreira da Silva ${ }^{6}$, Rafaela Araújo Oliveira ${ }^{7}$, Anne Caroline Rodrigues Barbosa ${ }^{7}$, Alessandra Justino Dionisio ${ }^{7}$, João Manuel Galhanas Mendes ${ }^{8}$, Gilson de Vasconcelos Torres ${ }^{9}$
\end{abstract}

\section{Abstract}

Objective: to analyze the association between the socio-demographic and health aspects to the quality of life $(\mathrm{QOL})$ of elderly peoplelinked to the ESF.

Methods: this is an analytical, cross-sectional study with a quantitative approach, carried out in two communities ascribed to the Family Health Strategy (ESF) of Rio Grande do Norte, Brazil, between December 2015 and March 2016. The data collection instruments were: a socio-demographic and pain characteristics questionnaire; Mini-Mental State Examination (MMSE), the Medical Outcomes Short-Form Health Survey (SF-36 Brazilian version). A descriptive and inferential analysis with $5.0 \%$ significance levelwere performed. The study followed the ethical precepts of research.

Results: In this age group studied, there is a significant association between younger elderly with the domains of functional capacity (Average 67.2 and $\rho$-value 0.032), emotional health presented average 82.0 ( $\rho$-value 0.040 ) and physical size (Average 51.4 and $\rho$-value 0.042). Among the aspects of health and QOL there was a statistical significance between the variable "pain in the last week", with the absence of pain associated with functional capacity (Average 76.7 and $\rho$-value 0.013) and emotional health (Average 96.1 and $\rho$-value
1 Nurse graduated, UFRN. Master in nursing, Program in Nursing at the UFRN. Member of the GPIPE. Brazil.

2 Nurse. PhD Professor at School of Nursing. University of Campinas. Brazil.

3 Nurse, agraduate, UFRN. Master student of the Graduate Program in Health Science (UFRN). Member of the GPIPE. Brazil.

4 Nutritionist, graduate by the UFRN. Master studentin the Graduate Program in Health Science, UFRN. Member of the Research Group Incubator Nursing Procedure, UFRN. Brazil.

5 Nurse, agraduate, UNP. Master student of the Graduate Program in Health Science, UFRN. Member, UFRN. Brazil.

6 Nurse, agraduate, UNP. Member of the Research Group Incubator Nursing Procedure, UFRN. Brazil.

7 Student nursing course. Scientific Initiation Scholar. Member of the Research Group Incubator Nursing Procedure, UFRN. Brazil.

8 Nurse, PhD in Nursing (Portuguese Catholic University, 2013). Professor and Chair without aggregation (Assembly of the Nursing School). Portugal.

9 Nurse, Post-Doctorate in Nursing in Évora/Portugal (2011), Ph.D. in Nursing/ EERP-USP (2000). Professor, UFRN, Scholarship at the Research Productivity PQ2/CNPq (2009/2012; 2012/2015;

2015/2018). Coordinator, GPIPE. Brazil.

Contact information:

Bruno Araújo da Silva Dantas

”b bruno_asd90@hotmail.com 
(0.019) These statistically significant differences occurred in the elderly of Santa Cruz.

Conclusion: regarding the association between socio-demographic and health aspects and QOL of the elderly, there was a significant between different variables and domains, with a strong association of QOL with age, marital status, pain and medication use.

\section{Keywords}

Elderly; Quality of Life; Aging; Elderly Health; Health Profile; Nursing.

\section{Introduction}

The population aging process raises several discussions about new ways to the health policies for the elderly [1]. At this stage of life, the elderly identify their old age according to their degree of dependence and changes in aging. Thus, the body image, autonomy, functionality, family support, mental health, and cognition are set as parameters [2].

The most evident changes in the old age are the functional decline identifying a varying level of limitation of movement, loss of muscle mass, as well as cognitive, visual and auditory acuity impairment [3]. When all these changesare associated with lifestyle habits, they are decisive factors for the vulnerability of these individuals to the risks to their health and their quality of life (QOL) [4].

In this sense, the World Health Organization (WHO) defines this construct as the perception of each one about their life situation, in a specific reality, observing a range of values related to the objectives and life expectations [5]. It also proposes the concept of active aging, including the maintenance of physical, mental and social potential as a QOL improvement strategy on aging [6].

When considering this subjectivity and active aging, several proposals are observed in the studies to measure these aspects, based on multiple domains and dimensions [7]. The instrument The Medical OutcomesStudy 36- Item Short Form-Health Survey (SF-36) is validated in Brazil and widely used in research, covering areas such as pain, functional capacity, physical limitations, emotional and social aspects, among others [7-8].

Given the complexity of the concept, there is a direct relationship with the emotional, cognitive, psychological and functional aspects [9]. When facing such some demands, the work of a multidisciplinary teamis required to ensure comprehensiveness in care for the elderly [10].

The Family Health Strategy (ESF) in Brazil is the main conductor of the primary health care of the Unified Health System (SUS), Brazilian system of health care. Thus, the ESF has a multidisciplinary team that should be present in the socio-cultural setting of the individual and his family [11]. Within this strategy, the policies for the older population predict different needs of this population, aiming to promote health and healthy aging [12].

The teams must have the ability to identify the demands inherent in the aging process, through the approach to the elderly, held through consultations, home visits and health promotion and prevention actions [13]. Within the perspective of the comprehensive care, the team must remain inserted in its midst, seeking the formation of links with the individual and his families, generating a trust relationship for a greater effectiveness of the planned actions [14].

Based on these, the research questions were established: What is the socio-demographic and health profile of the elderly linked to the ESF of Natal and Santa Cruz? What is the association of 
socio-demographic and health aspects in the quality of life of the elderly?

The objective of this research is to analyze the association between socio-demographic and health aspects with the QOL of elderly linked to the ESF.

\section{Methods}

\section{Methodological design}

This is ananalytical, cross-sectional study with a quantitative approach, performed in Igapó communities in the north of the city of Natal, Rio Grande do Norte (RN), the Dner neighborhood and the elderly clinic in the city of Santa Cruz/RN, Brazil. The study was held between December 2015 and March 2016.

\section{Type and location of the study}

The choice of these municipalities was due to the different socio-cultural and socio-demographic characteristics since Natal is a large city, being the state capital, and Santa Cruz is a municipality located within the state and with a smaller population.

Natal is a Brazilian city characterized by being the state capital with an estimated population of 862,044 inhabitants in 2014 [15]. The Family Health Unit (USF) of Igapó district covers three areas, divided into 15 micro areas and three teams registered in the ESF. The fortnightly meetings with the elderly are held in a space donated by the local parish due to the unavailability of appropriate physical space in their USF.

Santa Cruz in also a Brazilian city located $115 \mathrm{~km}$ from Natal. It is locatedin the Potiguar mesoregion, with an estimated population of 38,538 inhabitants in 2014 [15]. The USF of the Dner neighborhood has a team covering the area related to the neighborhood. The weekly activities with the elderly happen within the USF on a space available. Besides these activities, there are elderly linked to activities in the Clinical Physiotherapy School of theHealth and Sciences School ofTrairi (FACISA), UFRN.

\section{Population and sample}

It is noteworthy that this study is the initial stage of a case-controlresearch, in which a proposal was presented to the elderly belonging to two cities, places of this study, offering a plan with several multicentre interventions, focused on the improvement of QOL of the elderly. Thus, a group of 60 elderlywas formed, of which 30 belonged to Igapó (Natal), and the other 30 belonged to Santa Cruz (Dner and Clinical Physiotherapy School), being the case group or the intervention group. After the characterization of these individuals, another group was formed(control group), according to the same n (60 elderly), considering their respective municipalities and five socio-demographic characteristics to compare the purposes of the sample.

Therefore, the total sample was given due to the need to achieve statistical significance, and contemplate the relevant requirements to the chosen methodology, in this case, for the case-control study.

It is also emphasized that all the elderly population of the study, including those in the control group received the same invitation to receive the interventions enabling freedom of choice. For this study, the total n of 120 elderly was considered, dividing them according to their research scenarios.

\section{Instruments}

The instruments selected for the data collection were the questionnaire of socio-demographic data and characteristics of pain, which addresses the profile of the elderly, as well as information on the presence and intensity of pain and disease The Mini-Mental State Exam (MMSE) was also used to evaluate the status and cognitive of the participants, addressing functions of orientation, registration, attention, calculation, recall and language [16], serving as a parameter for inclusion or exclusion of individuals in the study. The Brazilian version validated of the quality 
of life questionnaire Medical Outcomes Short-Form Health Survey (SF-36) composed ofeight domains and two dimensions for the QOLof 36 questions for the measurement scale of each was also used [17].

\section{Variables}

For the presentation of the results, the choice of variables was based on the contents of each instrument and the objective of this study. Thus, the socio-demographic variable addresses the age considering elderly from 60 years old. The point is dividing the sample among younger elderly, and older elderlywas determined by the median values of the ages found.

As for the education, the elderly who reported up to three years of studywere consideredas a low level of education, according to MMSE parameters. The presence or absence of activity refers to the fact that the elderly have or not, any occupation (paid or unpaid). Family income was measured in minimum wages, with the value in 2016 amounting to $R \$$ 880.00 (eight hundred and eighty reais).

In the characterization of the health aspects, thesevere pain was considered when it was in a shorter space of time than six months, and the chronic pain was above this range, as ataxonomy of nursing diagnoses [18]. The same criteria for chronicity are assigned to the variable questioning about the presence of chronic diseases. The variable"other diseases"are the acute diseases.

\section{Data collection}

The data collection took place at predetermined days and directed to the activities of the elderly groups, and by active search in the community study, followed by home visits without prior notice. This search was held with the help of the community health agents (CHA), linked to the service at the ESF of Igapó and Dner, by knowing about the individuals living in the territory. There was a further process of data collection until it was reached the amount of 120 elderly.

\section{Inclusion and exclusion criteria}

For inclusion in the study, participants had to have aged 60 years, in accordance to the Elderly Statute [19], which the individual belonging to this age group is considered elderly in Brazil; registered in the health unit in their municipality as a patient during the collection period; having cognitive ability, measured by the cognitive screening tool MMSE, which considers the cutoff point of 17 points for individuals with three or fewer years of education (low education) and 24 points for those who have had four years of study or more. Individuals who did not include such criteria were excluded.

Thus, two elderly from Natal and one fromSanta Cruz were excluded after failing the MMSE cutoff. Two participants of Natal and three of Santa Cruz were approached and then they were excluded from the study because they had below the age established for this study.

The inclusion criteria in the study were participants aged 60 years old, in accordance with the Elderly Statute [19], which considered elderly in Brazil, the individual belonging to this age group; It is registered in the health unit in your municipality as a client during the collection period; present cognitive ability, measured by cognitive screening tool MMSE, which considers the cutoff point of 17 points for individuals with three or fewer years of education (low education) and 24 points for those who have had four years of study or more. Individuals who did not include such criteria were excluded.

Thus, two Christmas elderly and Santa Cruz were excluded after failing the MMSE cutoff. Two Christmas participants and three of Santa Cruz were approached and then excluded from the study because they have below the age established for this study.

\section{Analysis and data presentation}

For the tabulation and analysis of the data, Microsoft Excel 2013 and SPSS IBM version 20.0 programs were used. For nominal and ordinal variables ofthe socio-demographic and healthcharacteristics, the nonparametric Pearson's chi-square test was applied 
to verify the significance of the dispersion between the compared variables, using the Fisher's exact test when necessary, which is a more appropriate test for such a situation.

When testing the scalar variables (in this SF-36), the Mann-Whitney $U$ testwas used, nonparametric for analysis between the independent variable domains and dimensions of the SF-36 and the study places. Confidence Interval $(\mathrm{Cl})$ of $95 \%$ and significant findings with $\rho$-value $<0.05$ were adopted.

Thus, the following statistical hypotheses were tested: Null Hypothesis $\left(\mathrm{H}^{0}\right)$ : The QOL scores have no association with socio-demographics and health aspects; and alternative Hypothesis $\left(H^{1}\right)$ : The QOL scores have association with socio-demographics and health aspects.

\section{Ethical aspects}

Given the resolution of the National Council of Health 466/12 that solves about human studies [20], this research received prior approval by the Ethics Committee on Research at the University Hospital Onofre Lopes (CEP/HUOL) under Certificate of Presentation for Ethics Assessment (CAAE) number 21996313.7.0000.5537. Before the interviews, the Informed Consent Form (TCLE) was given to the participants with the necessary guidance and assurance, subsequently signed voluntarily by them.

\section{Results}

The study sample had 120 elderly people, ascribed to the ESF. Among the socio-demographic criteria (Table 1), there was a predominance of female $(83.3 \%)$ and aged between 60 and 71 years old (61.7\%). The profile was similar when analyzingthe two scenarios isolated.

Santa Cruz had $36.7 \%$ of the elderly with ahigher income than the minimum wage, while in Natal, $20.0 \%$ had that income. These data had statistically significant difference $(p<0.001)$.
Table 1. Socio-demographic characterization of the elderlyaccording to the study location. Natal and Santa Cruz, Rio Grande do Norte, Brazil, 2016. $(n=120)$.

\begin{tabular}{|c|c|c|c|c|c|c|c|}
\hline \multirow{2}{*}{$\begin{array}{c}\text { Socio- } \\
\text { demographic } \\
\text { characterization }\end{array}$} & \multicolumn{2}{|c|}{ Natal } & \multicolumn{2}{|c|}{$\begin{array}{l}\text { Santa } \\
\text { Cruz }\end{array}$} & \multicolumn{2}{|c|}{ Total } & \multirow[t]{2}{*}{ P-value* } \\
\hline & $n$ & $\%$ & $n$ & $\%$ & $n$ & $\%$ & \\
\hline \multicolumn{8}{|l|}{ Gender } \\
\hline Female & 50 & 41.7 & 50 & 41.7 & 100 & 83.3 & \multirow{2}{*}{1.000} \\
\hline Male & 10 & 8.3 & 10 & 8.3 & 20 & 16.7 & \\
\hline \multicolumn{8}{|c|}{ Age group (years old) } \\
\hline 60 to 75 & 44 & 36.7 & 50 & 41.7 & 94 & 78.3 & \multirow{2}{*}{0.184} \\
\hline 76 to 91 & 16 & 13.3 & 10 & 8.3 & 26 & 21.7 & \\
\hline \multicolumn{8}{|l|}{ Education (years) } \\
\hline Up to 3 & 31 & 25.8 & 30 & 25.0 & 61 & 50.8 & \multirow{2}{*}{0.855} \\
\hline$>3$ & 29 & 24.2 & 30 & 25.0 & 59 & 49.2 & \\
\hline \multicolumn{8}{|l|}{ Marital Status } \\
\hline With a partner & 29 & 24.2 & 34 & 28.3 & 63 & 52.5 & \multirow[b]{2}{*}{0.361} \\
\hline $\begin{array}{l}\text { Without a } \\
\text { partner }\end{array}$ & 31 & 25.8 & 26 & 21.7 & 57 & 47.5 & \\
\hline \multicolumn{8}{|l|}{ Family income } \\
\hline $\begin{array}{l}\text { Up to1 minimum } \\
\text { wage }\end{array}$ & 36 & 30.0 & 16 & 13.3 & 52 & 43.3 & \multirow{2}{*}{$<0.001$} \\
\hline $\begin{array}{l}>1 \text { minimum } \\
\text { wage }\end{array}$ & 24 & 20.0 & 44 & 36.7 & 68 & 56.7 & \\
\hline \multicolumn{8}{|l|}{ Living with } \\
\hline A partner & 23 & 19.2 & 31 & 25.8 & 54 & 45.0 & \multirow{6}{*}{0.060} \\
\hline $\begin{array}{l}\text { Children/ } \\
\text { grandchildren }\end{array}$ & 25 & 20.8 & 21 & 17.5 & 46 & 38.3 & \\
\hline Alone & 12 & 10.0 & 05 & 4.2 & 17 & 14.2 & \\
\hline Other** & 00 & 0.0 & 03 & 2.5 & 03 & 2.5 & \\
\hline Retired & 51 & 42.5 & 43 & 35.8 & 94 & 78.3 & \\
\hline $\begin{array}{l}\text { Taking care of } \\
\text { the house }\end{array}$ & 08 & 6.7 & 13 & 10.8 & 21 & 17.5 & \\
\hline \multicolumn{8}{|l|}{ Job situation } \\
\hline Working & 01 & 0.8 & 03 & 2.5 & 04 & 3.3 & \multirow[b]{2}{*}{0.276} \\
\hline $\begin{array}{l}\text { Without } \\
\text { occupation }\end{array}$ & 00 & 0.0 & 01 & 0.8 & 01 & 0.8 & \\
\hline \multicolumn{8}{|l|}{ Having an activity } \\
\hline Yes & 58 & 48.3 & 57 & 47.5 & 115 & 95.8 & \multirow{2}{*}{1.000} \\
\hline No & 02 & 1.7 & 03 & 2.5 & 05 & 4.2 & \\
\hline
\end{tabular}


On the profile of the health aspects (Table 2), using the total sample as areference, it was shown the presence of pain in $73.3 \%$, with apredominance of chronic pain $(53.3 \%)$ and, within a measurement scale, $33.3 \%$ reported moderate pain. Ranking the sites of the pain, the dorsal region was highlighted (24.2\%), followed by the lower limbs (LL) (20.0\%) and upper limbs (UL) (8.3\%). On the presence of

Table 2. Characterization of the health aspects in the elderly according to the study place. Natal and Santa Cruz, Rio Grande do Norte, Brazil, 2016. $(n=120)$.

\begin{tabular}{|c|c|c|c|c|c|c|c|}
\hline \multirow{3}{*}{$\begin{array}{c}\text { Characterization } \\
\text { of the heath } \\
\text { aspects }\end{array}$} & \multicolumn{4}{|c|}{ Study place } & \multirow{2}{*}{\multicolumn{2}{|c|}{ Total }} & \multirow{3}{*}{$\begin{array}{c}\text { P- } \\
\text { value* }\end{array}$} \\
\hline & \multicolumn{2}{|c|}{ Natal } & \multicolumn{2}{|c|}{$\begin{array}{c}\text { Santa } \\
\text { Cruz }\end{array}$} & & & \\
\hline & $n$ & $\%$ & $n$ & $\%$ & $n$ & $\%$ & \\
\hline
\end{tabular}

Pain in the last week

\begin{tabular}{|l|l|l|l|l|l|l|l|}
\hline Yes & 45 & 37.5 & 43 & 35.8 & 88 & 73.3 & \\
\hline No & 15 & 12.5 & 17 & 14.2 & 32 & 26.7 & 0.680 \\
\hline
\end{tabular}

Type of pain

\begin{tabular}{l|l|l|l|l|l|l|l|}
\hline Chronic & 33 & 27.5 & 31 & 25.8 & 64 & 53.3 & 0.822 \\
\hline Severe & 13 & 10.8 & 12 & 10.0 & 25 & 20.8 & \\
\hline
\end{tabular}

Intensity of the pain

\begin{tabular}{|l|c|c|c|c|c|c|c|c|}
\hline Absent & 14 & 11.7 & 17 & 14.2 & 31 & 25.8 & \\
Mild & 08 & 6.7 & 10 & 8.3 & 18 & 15.0 & \\
\hline Moderate & 21 & 17.5 & 19 & 15.8 & 40 & 33.3 & 0.825 \\
\hline Intense & 17 & 14.2 & 14 & 11.7 & 31 & 25.8 & \\
\hline
\end{tabular}

Place of the pain

\begin{tabular}{|l|c|c|c|c|c|c|c|}
\hline Dorsal & 12 & 10.0 & 17 & 14.2 & 29 & 24.2 & \\
\cline { 1 - 2 } & 14 & 11.7 & 10 & 8.3 & 24 & 20.0 & \\
\hline MMSS\# & 04 & 3.3 & 06 & 5.0 & 10 & 8.3 & 0.502 \\
Generalized & 04 & 3.3 & 05 & 4.2 & 09 & 7.5 & \\
Lumbar & 06 & 5.0 & 02 & 1.7 & 08 & 6.7 &
\end{tabular}

\begin{tabular}{|c|c|c|c|c|c|c|c|}
\hline \multicolumn{8}{|c|}{ Chronic Diseases } \\
\hline Yes & 56 & 46.7 & 50 & 41.7 & 106 & 88.3 & \multirow{2}{*}{$0.153^{8}$} \\
\hline No & 04 & 3.3 & 10 & 8.3 & 14 & 11.7 & \\
\hline \multicolumn{8}{|c|}{ Others diseases } \\
\hline Yes & 27 & 22.5 & 21 & 17.5 & 48 & 40.0 & \multirow{2}{*}{0.295} \\
\hline No & 33 & 27.5 & 39 & 32.5 & 72 & 60.0 & \\
\hline \multicolumn{8}{|c|}{ Usingmedicine } \\
\hline Yes & 55 & 45.8 & 47 & 39.2 & 102 & 85.0 & \multirow{2}{*}{0.410} \\
\hline No & 05 & 4.2 & 13 & 10.8 & 18 & 15.0 & \\
\hline
\end{tabular}

chronic diseases, $88.3 \%$ of seniors responded positively, while $60.0 \%$ reported not having other diseases, not considered chronic. Thus, the use of medicine was present in $85.0 \%$ of the elderly. Despite the differences in frequency aspects of health, any variable showed a significant difference.

The Table 3 shows the scores of the SF-36, domains and dimensions andatotalof the two municipalities. Regarding the domains of the SF-36, an approximate average was observedwhen comparing the two scenarios. The domain emotional aspects, had higher averages in Natal, 78.3 (SD=39.2) and Santa Cruz, 76.6 (SD=40.8), but there was no significant difference between the two municipalities. It is also observed that these values are close to the average of the total sample in their domain, 77.5 (SD=39.9).

Table 3. Distribution of the average scores of domains and dimensions of SF-36 according to the study place. Natal and Santa Cruz, Rio Grande do Norte, Brazil, 2016. $(n=120)$

\begin{tabular}{|c|c|c|c|c|}
$\begin{array}{c}\text { Quality of } \\
\text { Life }\end{array}$ & Natal & $\begin{array}{c}\text { Santa } \\
\text { Cruz }\end{array}$ & $\begin{array}{c}\text { U of Mann- } \\
\text { Whitney }\end{array}$ & Total \\
\hline (SF-36) & $\begin{array}{c}\text { Average } \\
\text { (SD) }\end{array}$ & $\begin{array}{c}\text { Average } \\
\text { (SD) }\end{array}$ & P-value & $\begin{array}{c}\text { Average } \\
\text { (SD) }\end{array}$ \\
\hline
\end{tabular}

Domains

\begin{tabular}{|c|c|c|c|c|}
\hline $\begin{array}{l}\text { Emotional } \\
\text { aspects }\end{array}$ & $78.3(39.2)$ & $76.6(40.8)$ & 0.924 & 77.5 (39. \\
\hline unctional & $63.1(26.4)$ & $64.3(26.2)$ & 0.809 & $63.7(26.2)$ \\
\hline $\begin{array}{l}\text { lental } \\
\text { ealth }\end{array}$ & $58.0(11.6)$ & $59.6(8.0)$ & 0.844 & 58.8 (10. \\
\hline tysical & $54.6(47.2)$ & $59.1(45.8)$ & 0.622 & 56.9 (46.4) \\
\hline tality & $56.9(15.4)$ & $54.6(14.9)$ & 0.376 & $55.9(15.2)$ \\
\hline $\begin{array}{l}\text { eneral } \\
\text { ealth }\end{array}$ & $44.6(16.3)$ & 39.5 (16.3) & 0.083 & $42.1(16.4)$ \\
\hline $\begin{array}{l}\text { ocial } \\
\text { unction }\end{array}$ & $48.9(16.1)$ & $49.6(13.0)$ & 0.372 & $49.2(14.6)$ \\
\hline ain & 36.3 (21.8) & 33.17 (20.6) & 0.406 & $34.7(21.2)$ \\
\hline \multicolumn{5}{|l|}{ Dimensions } \\
\hline $\begin{array}{l}\text { Mental } \\
\text { ealth }\end{array}$ & $57.3(9.6)$ & $56.0(10.6)$ & 0.457 & $56.7(10.1)$ \\
\hline $\begin{array}{l}\text { hysical } \\
\text { ealth }\end{array}$ & $51.1(10.4)$ & $50.1(10.9)$ & 0.665 & $50,6(10,6)$ \\
\hline tal score & $55.1(8.8)$ & $54.6(10.2)$ & 0.902 & $54.9(9.5)$ \\
\hline
\end{tabular}


Table 4. Association between socio-demographic aspects and QOL (SF-36) in the elderly according to the place. Natal and Santa Cruz, Rio Grande do Norte, Brazil, 2016. (n=120).

\begin{tabular}{|c|c|c|c|c|c|c|c|c|}
\hline \multirow{4}{*}{$\begin{array}{l}\text { Socio- } \\
\text { demographic } \\
\text { aspects }\end{array}$} & \multicolumn{6}{|c|}{ Quality of Life } & \multirow{3}{*}{\multicolumn{2}{|c|}{ Total score }} \\
\hline & \multicolumn{4}{|c|}{ Domains } & \multirow{2}{*}{\multicolumn{2}{|c|}{$\begin{array}{l}\text { Dimensions } \\
\text { Physical health }\end{array}$}} & & \\
\hline & \multicolumn{2}{|c|}{ Functional capacity } & \multicolumn{2}{|c|}{ Emotional health } & & & & \\
\hline & Natal & S. Cruz ** & Natal & S. Cruz** & Natal & S. Cruz** & Natal & S. Cruz** \\
\hline \multicolumn{9}{|l|}{ Age group } \\
\hline 60 to 75 years old & 65.4 & 67.2 & 72.0 & 82.0 & 51.7 & 51.4 & 54.7 & 56.1 \\
\hline 76 to 91 years old & 56.9 & 50.0 & 95.8 & 50.0 & 49.5 & 43.7 & 56.1 & 47.1 \\
\hline P-value* & 0.287 & 0.032 & 0.028 & 0.040 & 0.461 & 0.042 & 0.569 & 0.014 \\
\hline \multicolumn{9}{|l|}{ Marital Status } \\
\hline With a partner & 65.0 & 69.7 & 80.5 & 87.2 & 49.6 & 51.3 & 54.1 & 56.6 \\
\hline Without a partner & 61.4 & 57.3 & 76.3 & 62.8 & 52.5 & 48.8 & 56.0 & 52.0 \\
\hline P-value* & 0.568 & 0.037 & 0.681 & 0.043 & 0.286 & 0.374 & 0.317 & 0.107 \\
\hline \multicolumn{9}{|l|}{ Family income } \\
\hline Up to 1 wage & 60.5 & 50.6 & 75.9 & 60.4 & 50.3 & 47.2 & 54.6 & 50.4 \\
\hline$>$ Wage & 67.1 & 69.3 & 81.9 & 82.6 & 52.4 & 51.2 & 55.7 & 56.2 \\
\hline P-value* & 0.368 & 0.008 & 0.697 & 0.060 & 0.441 & 0.216 & 0.629 & 0.056 \\
\hline \multicolumn{9}{|l|}{ Having an activity } \\
\hline Yes & 64.5 & 64.6 & 77.6 & 77.1 & 51.3 & 49.7 & 55.3 & 54.2 \\
\hline No & 22.5 & 58.3 & 66.6 & - & 44.5 & 58.6 & 48.0 & 59.0 \\
\hline P-value* & 0.034 & 0.653 & 0.547 & 0.798 & 0.366 & 0.209 & 0.307 & 0.377 \\
\hline
\end{tabular}

Table 5. Association between health aspects and QOL(SF-36) of the elderly. Natal and Santa Cruz, Rio Grande do Norte, Brazil, 2016. ( $n=120)$

\begin{tabular}{|c|c|c|c|c|c|c|c|c|}
\hline \multirow{4}{*}{ Health aspects } & \multicolumn{6}{|c|}{ Quality of Life } & \multirow{2}{*}{\multicolumn{2}{|c|}{ Dimension }} \\
\hline & \multicolumn{6}{|c|}{ Domains } & & \\
\hline & \multicolumn{2}{|c|}{ Functional } & \multicolumn{2}{|c|}{ Body pain } & \multicolumn{2}{|c|}{ Emotional } & \multicolumn{2}{|c|}{ Mental health } \\
\hline & Natal & S. Cruz** & Natal & S. Cruz ${ }^{* *}$ & Natal & S. Cruz** & Natal & S. Cruz** \\
\hline \multicolumn{9}{|l|}{ Pain in the last week } \\
\hline Yes & 61.2 & 59.4 & 39.1 & 42.8 & 74.1 & 69.0 & 56.3 & 54.3 \\
\hline No & 69.0 & 76.7 & 28.0 & 8.8 & 91.1 & 96.1 & 60.5 & 60.2 \\
\hline P-value* & 0.342 & 0.013 & 0.115 & $<0.001$ & 0.161 & 0.019 & 0.124 & 0.026 \\
\hline \multicolumn{9}{|l|}{ Type of pain } \\
\hline Chronic & 55.4 & 60.3 & 42.1 & 41.3 & 64.6 & 69.9 & 54.6 & 53.8 \\
\hline Severe & 71.9 & 57.1 & 34.6 & 46.7 & - & 66.6 & 59.8 & 55.7 \\
\hline Absent & 73.2 & 76.7 & 24.3 & 8.8 & 90.5 & 96.1 & 61.4 & 60.2 \\
\hline P-value* & 0.040 & 0.044 & 0.054 & $<0.001$ & 0.007 & 0.062 & 0.052 & 0.080 \\
\hline \multicolumn{9}{|l|}{ Use of medication } \\
\hline Yes & 62.1 & 60.2 & 36.7 & 33.4 & 78.2 & 73.7 & 57.2 & 55.6 \\
\hline No & 75.0 & 79.2 & 32.0 & 32.3 & 80.0 & 97.2 & 58.4 & 57.4 \\
\hline P-value* & 0.403 & 0.020 & 0.603 & 0.978 & 0.856 & 0.275 & 0.795 & 0.794 \\
\hline
\end{tabular}


Table 4 shows the association between the sociodemographic and QOL characteristics of the elderly people in Natal and Santa Cruz.

In the age group, there is a significant association between the younger elderly with functional capacity (Average 67.2 and $\rho$-value 0.032). Emotional health presented average 82.0 ( $\rho$-value 0.040) and physical dimension (Average 51.4 and $\rho$-value 0.042). All these data was in Santa Cruz. In Natal, considering the emotional health domain, there was a predominance of the older subjects (Average 95.8 and $\rho$-value 0.040).

Regarding the association between health aspects and QOL of the elderly, Table 5 shows a significant association between the variable "pain in the last week", considering the absence of pain with functional capacity (Average 76.7 and $\rho$ - value 0.013) and emotional health (Average 96.1 and $\rho$-value (0.019), both among the participants of Santa Cruz. The non-use of medication (Average 79.2) showed a statistically significant difference for the association with the functional capacity domain ( $\rho$-value 0.020 ) in the municipality of Santa Cruz.

\section{Discussion}

This research highlights the analysis of socio-demographic and health aspects and establishes the comparative QOL among the elderly of Natal and Santa Cruz cities. The predominance of women in the sample approaches the reality of other findings in the literature [21-23]. Even before this majority in both scenarios, gender does not appear significantly associated with QOL.

In another Brazilian study that used the WHOQOOL-OLD instrument, there were better QOL scores among men than women, which in turn,they had a greater burden of disease, physical limitations and depressive symptoms [24]. In Natal and Santa Cruz, there wasa prevalence of chronic diseases in women.

The problems and chronic diseases were stood out for the two scenarios studied, verifying Santa Cruz with a slightly lower number of diseased elderly. A cohort study showed that these comorbidities have agreat impact on the QOL of the elderly, especially disability and physical dependence [25]. Different to this finding, Natal and Santa Cruz isolated, showed no significant association between the presence of chronic diseases with QOL. However, considering the total sample, that is the union between the two scenarios, there was a significant association between functional capacity domain and the absence of chronic diseases.

Other recent studies indicate that the presence of diseases and comorbidities may have their relief impact when the elderly get healthy behaviors, considered positive to the old age, such as good nutrition and physical exercises [26-28].Also, active elderly people have a tendency to a lower burden of disease and better health status than the idle elderly [29]. Thus, there is a precedent for interventions to exercise and healthy eating.

In this sense, Natal and Santa Cruz had the domains of functional capacity and physical health as the best assessed by the SF-36. The functionality presented a significant difference in association with QOL in a study of Canadian elderly [30]. In another study with institutionalized elderly, there was a functional performance of medium to good, and the decline of this aspect with advancing age was identified [23]. This data is similar to data found in Santa Cruz and in the total sample, where there was astrong association between functional domain and younger elderly. A similar situation was observed to evaluate the physical dimension.

Thus, it is observed that interventions promoting physical activity to adults have good efficacy even having alow frequency [31]. For the prevention of disabilities and other health problems, motivational approach proposals presented positive results, and improve the autonomy of the elderly in their social and functional context [32].

Among the other domains stood out in Natal and Santa Cruz, the mental health showed results 
above the median QOL scale. Strongly linked to this aspect, the presence of depression gained significant focus in the literature to assess the mental and emotional aspects, relating them to the QOL of the elderly [23]. Reduced average QoL in elderly patients with symptoms of depressionwas found in a recent study, compared with non-depressed elderly [21]. In Santa Cruz, there is the domain of the emotional aspects associated strongly with the age group of younger elderly, with the presence of the company and the absence of pain. In Natal, there is a strong association between the same domain for older elderlyand favor of the absence of in the total sample pain.

A study points out that the mental health and physical performance domains showed better results on average in the evaluation in the elderly [33], which resembles with the results of this research. A recently international cohort study highlights a strong association between increased quality of liferelated to health and reducing depression levels in the samples [34]. It was observed that in Santa Cruz, the emotional aspects were anegative and significant association with the age of the elderly and the absence of spouse or partner.

Given this finding, the family supportis identified as a major influencer in elderly's QOL, considered a determining factor and having adirect relationship with the emotional aspects [35]. In Poland, where the family emotional supportwas investigated, found asignificant negative difference in the elderly compared to non-institutionalized elderly [22]. In Natal and Santa Cruz, there is a balance between the elderly who have and those who do not have a partner. Despite this finding, the presence of family members, such as children and grandchildren, at the residence was predominant, which may be a positive factor to them.

In addition to the family support, the elderly need social interaction within his context [36]. The World Health Organization (WHO) identifies the active concept of aging in a comprehensive way in which the elderly must have health opportunity, and the political and social context, exercising their citizenship in a participatory way [6].

Turning to the international context, the United States of America (USA) a population-based study indicated that the presence of social support in searchable elderly is inversely proportional to the level of brittleness, which in turn, impacts significantly on QV [37]. In a Chinese city, there was a reduction in scores in the social field, by increasing weakness identified in the elderly in the sample [38]. It is observed that in both cities surveyed, the social function had the lowest average among the other areas, with values lower half of the SF-36 scale. Despite this finding, there was no significant association between the social and socio-demographic and health variables.

In this way, the importance of promoting the interaction between individuals of different ages, different genders, and culturesis highlighted. Results found in Brazil associate the presence of diseases and comorbidities to the fact that the elderly do not leave the house. By practicing this act, the elderly have considerable potential for socializing, with influence in their QOL [36]. Thus, it identifies the relationship between the social and the physical.

Therefore, it is necessary to use measures to improve the QOL in the elderly. The use of technologies as tools for interventions in the elderly is increasingly common, presenting results improving cognition, promoting social inclusion, and also preventing disease and mental health problems [2, 39-40]. Promotion strategies for coping, improved self-esteem and adapting to daily life activities are presented for a healthy aging [33].

Natal and Santa Cruz showed a predominance of elderly people who have some activity. However, there were scores of functional and physical domains, classified as good and average, respectively. Thus, further investigation is necessary on what type of activity these seniors perform along with their level of complexity to be better detailed the adequacy of their movements and measure their 
health benefits, to improve the measures of $\mathrm{QOL}$ better.

Given these findings, new proposals for interventions are indicated to improve the social domain, as well as maintenance of other domains, however well evaluated. As discussed in this paper, the use of technological resources and digital inclusion of the elderly appears as a choice methodology to work interventions accordingly.

Limitations and difficulties of this research were the cross-sectoral cut, the extended period of collection and the adverse conditions faced by researchers in the active search for participants.

\section{Conclusion}

This research showed that the characteristics in Natal and Santa Cruz had no significant association with QOL observed when comparing the two scenarios. However, drawing their profile enables deeper into each of these aspects, to positively affect the QL, as well as efforts to reduce the vulnerability of the elderly.

Regarding the association between socio-demographic and health aspects and QOL of the elderly, there was significance between different variables and domainsgiventhe strong association of QOL with the age group, marital status, pain and the use of medicines. Thus, the alternative hypothesis ( $\mathrm{H} 1)$ is accepted in which the presence of the association between socio-demographic and health variables with the domains of QOL are considered.

Given the complexity of the concept of QOL, as well as the domains that comprise it, it is highlighted the need for further deepening and evaluation of each of them. Such research would be aimed at better accuracy in assessing them, providing accurate and impactful interventions, with optimal effectiveness.

\section{References}

1. World Hearth Organization (WHO). World Report on Ageing and Health. WHO Library Cataloguing-in-Publication [online]. 2015 [cited 2016 jul 06]. Available from: http://apps.who.int/iris/ bitstream/10665/186463/1/9789240694811 eng.pdf?ua=1

2. Hein MA, Aragaki SS. Saúde e envelhecimento: um estudo de dissertações de mestrado brasileiras (2000-2009). Ciênc. Saúde Coletiva. 2012; 17(8): 2141-50.

3. Garatachea N, Pareja-Galeano H, Sanchis-Gomar F, SantosLozano A, Fiuza-Luces C, Morán M, et al. ExerciseAttenuatesthe Major Hallmarks of Aging. Rejuv. Res. 2015; 18 (1): 57-89.

4. Varela FRA, Ciconelli RM, Campolina AG, Soarez PC. Quality of life evaluation of frail elderly in Campinas, São Paulo. Rev Assoc Med Bras. 2015; 61 (5): 423-430

5. World Hearth Organization (WHO). The WHOQOL Group 1995. The World Health Organization quality of life assessment (WHOQOL): position paper from the World Health Organization. Social Science and Medicine. 1995; 10:1403-1409.

6. World Hearth Organization (WHO). Active aging: a policy framework [online]. 2002 [cited 2016 jul 06]. Available from: http://apps.who.int/iris/bitstream/10665/67215/1/WHO NMH $\mathrm{NPH}$ 02.8.pdf

7. Cruz LN. Fleck MPA, Oliveira MR, Camey SA, Hoffmann JF, Bagattini AM, et al. Health-related quality of life in Brazil: normative data for the SF-36 in a general population sample in the south of the country. Ciênc. Saúde Coletiva. 2013; 18(7): 1911-21.

8. Oliveira-Campos M, Rodrigues-Neto JF, Silveira MF, Neves DMR, Vilhena JM, Oliveira JF, et al. Impacto dos fatores de risco para doenças crônicas não transmissíveis na qualidade de vida. CiêncSaúdeColetiva. 2013; 18(3): 873-82.

9. Ferreira FPC, Bansi LO, Paschoal SMP. Serviços de atenção ao idoso e estratégias de cuidado domiciliares e institucionais. Rev. Bras. Geriatr. Gerontol. [online] 2014 [cited 2016 jul 14]; 17(4): 911-26. Available from: http://www.scielo.br/pdf/rbgg/ v17n4/1809-9823-rbgg-17-04-00911.pdf

10. Palgi Y, Shrira A, Zaslavsky O. Quality of life attenuates agerelated decline in functional status of older adults. Qual Life Res. 2015; 24: 1835-43.

11. Silva LMS, Fernandes MC, Mendes EP, Evangelista NC, Torres RAM. Trabalho interdisciplinar na Estratégia Saúde da Família: enfoque nas ações de cuidado e gerência. Rev. enferm. UERJ. [online] 2012 [cited 2016 jul 14]; 20 (esp.2): 784-8. Available from: http://www.e-publicacoes.uerj.br/ojs/index. php/enfermagemuerj/article/view/6024/4329

12. Brasil. Ministério da Saúde. Envelhecimento e saúde da pessoa idosa, $1^{\text {a }}$ edição. Secretaria de Atenção à Saúde. Departamento de Atenção Básica. Brasília, 2007.

13. Pilger C, Dias GF, Kanawava C, Baratieri T, Carreira L. Compreensão sobre o envelhecimento e ações desenvolvidas pelo enfermeiro na atenção primária à saúde. Ciência y Enfermeria. 2013; XIX (1): 61-73.

14. Polaro SHI, Gonçalvez LHT, Alvarez AM. Construindo o fazer gerontológico pelas enfermeiras das Unidades de Estratégia Saúde da Família. Rev Esc Enferm USP. 2013; 47(1):160-7 
15. InstitutoBrasileiro de Geografia e Estatística (IBGE). Censodemográfico. 2014.

16. Gluhm S, Goldstein J, Loc K, Colt A, Liew CV, Corey-Bloom J. Cognitive performance on the mini-mental state examination and the montreal cognitive assess menta cross the health yadult ifes pan. CognBehav Neurol. 2013; 26(1): 1-5.

17. Ciconelli RM, Ferraz MB, Santos W, Meinão I, Quaresma MR. Tradução para a línguaportuguesa e validação do questionáriogenérico de avaliação de qualidade de vida (Brasil SF-36). Rev bras reumatol. [online] 1999 [cited 2016 jul 12]; 39(3): 143-50. Available from: http://www.ufjf.br/ renato nunes/files/2014/03/Valida\%C3\%A7\%C3\%A3o-doQuestion\%C3\%A1rio-de-qualidade-de-Vida-SF-36.pdf

18. NANDA I. Diagnósticos de Enfermagem da NANDA Internacional 2012-2014. Traduzido por: Regina Machado Garcez. Edição Artmed, 2013

19. Ministério da Saúde. Estatuto do Idoso / Ministério da Saúde - 3. ed., 2. reimpr. - Brasília : Ministério da Saúde, 70 p., 2013.

20. Diário Oficial da União. Resolução 466, de 12 de Dezembro de 2012. Diário Oficial da União, Ministério da Saúde, 2012.

21. Keshavarzi S, Ahmadi SM, Lankarani KB, The Impact of Depression and Malnutrition on Health-Related Quality of Life Among the Elderly Iranians. Global Journal of Health Science. 2015; 7(3): 161-70.

22. Cybulski M, Krajewska-Kulak E, Jamiolkowski, J. Preferred health behaviors and quality of life of the elderly people in Poland. Clinical Interventions in Aging. 2015;10: 1555-64.

23. Muszalik M, Kornatowski T, Zielińska-Więczkowska H, KędzioraKornatowska K, Dijkstra A. Functional assessment of geriatric patients in regard to health-related quality of life (HRQoL). Clinical Interventions in Aging. 2015; 10: 61-7.

24. Campos ACV, Ferreira EF, Vargas AMD, Albala C. Aging, Gender and Quality of Life (AGEQOL) study: factors associated with good quality of life in older Brazilian community dwelling adults. Health andQualityof Life Outcomes. 2014; 12 (166): 1-11.

25. Forjaz MJ, Rodriguez-Blanzquez C, Ayala A, RodriguezRodriguez V, Pedro-Cuesta J, Garcia-Gutierrez S, et al. Chronic conditions, disability, and quality of life in older adults with multimorbidity in Spain. European Journal of Internal Medicine. 2015;26: 176-81

26. Garin N, Olaya B, Moneta MV, Miret M, Lobo A, Ayuso-Mateos $J$, et al. Impact of Multimorbidity on Disability and Quality of Life in the Spanish Older Population. PLOS ONE. 2014; 9(11): 1-12.

27. Atlas A, Grimmer K, Kennedy K. Early indications that low mental quality of life scores in recently unwell older people predict downstream functional decline. Clinical Interventions in Aging 2015; 10: 703-12.

28. Yamada $Y$, Merz L, Kisvetrova H. Quality of life and comorbidity among older home care clients: role of positive attitudes toward aging. Qual Life Res. 2015; 24: 1661-7.

29. Lai CKY, Chan EA, Chin KCW. Who are the healthy active seniors? A cluster analysis. BMC Geriatrics. 2014; 14(127): 1-7.
30. Davis JC, Bryan S, Li LC, Best JR, Hsu CL, Gomez C, et al. Mobility and cognition are associated with wellbeing and health related quality of life among older adults: a cross-sectional analysis of the Vancouver Falls Prevention Cohort. BMC Geriatrics. 2015; 15(75): 1-7.

31. Quehenberger V, Cichocki M, Krajic K. Sustainable effects of a low-threshold physical activity intervention on health-related quality of life in residential aged care. Clinical Interventions in Aging. 2014;9:1853-64.

32. Morgan GS, Haase AM, Campbell R, Ben-Shlomo Y. Physical Activity facilitation for Elders (PACE): study protocol for a randomized controlled trial. Trials. 2015; 16(91): 1-7.

33. Ziólkowski A, Blachnio A, Pachalska M. An evaluation of life satisfaction and health - Quality of life of senior citizens. Annals of Agricultural and Environmental Medicine. 2015; 22(1): 14751 .

34. Hajek A, Brettschneider C, Ernst A, Lange C, Wiese B, Prokein J et al. Complex coevolution of depression and health-related quality of life in old age. Qual Life Res. 2015; 24: 2713-22.

35. Marques EMBG, Sánches CS, Vicario BP. O apoio como fator promotor da qualidade de vida do idoso. Pedagogia Social. 2014; 23: 253-71.

36. Morsch P, Pereira GN, Navarro JHN, Trevisan MD, Lopes DGC, Bós AJC. Características clínicas e sociais determinantes para o idoso sair de casa. Cad. SaúdePública. 2015; 31(5): 1025-34.

37. PeekMK,Tement RS, Ray LA, Ottenbacher KJ. Social support, stressors, and frailty among older Mexican American adults. The Journals of Gerontology. 2012; 67(6): 755- 64.

38. Chang Y, Chen W, Lin F, Fang W, Yen $M$, Hsieh C, et al. Frailty and Its Impact on Health Related Quality of Life: A Cross Sectional Study on Elder Community-Dwelling Preventive Health Service Users. PLOS One. 2012; 7(5): 1-5.

39. Callari TC, Ciairano S, Re A. Elderly-technology interaction: accessibility and acceptability of technological devices promoting motor and cognitive training. Work. 2012; 41: 362-9.1

40. Gustafson Sr DH, McTavish S, Gustafson Jr DH, Mahoney JE, Johnson RA, Lee JD, et al. The effect of an information and communication technology (ICT) on older adults' quality of life: study protocol for a randomized control trial. Trials. 2015; 16(191): 1-12.

Publish in International Archives of Medicine

International Archives of Medicine is an open access journal publishing articles encompassing all aspects of medical science and clinical practice. IAM is considered a megajournal with independent sections on all areas of medicine. IAM is a really international journal with authors and board members from all around the world. The journal is widely indexed and classified Q2 in category Medicine. 